\title{
DAMPAK BANJIR TERHADAP PENDAPATAN PETANI PADI DI PINGGIR DANAU SINGKARAK NAGARI PANINGGAHAN KECAMATAN JUNJUNG SIRIH KABUPATEN SOLOK
}

\author{
Meri Andani ${ }^{1}$, Yurni Suasti ${ }^{2}$, Ahyuni ${ }^{2}$ \\ Program Studi Pendidikan Geografi \\ Fakultas Ilmu Sosial, Universitas Negeri Padang \\ Email meriandani0497@gmail.com
}

\begin{abstract}
Abstrak
Penelitian ini bertujuan untuk mengetahui dampak banjir terhadap pendapatan petani padi di Pinggir Danau Singkarak Nagari Paninggahan Kecamatan Junjung Sirih Kabupaten Solok. Jenis Penelitian ini adalah deskriptif dengan pendekatan kuantitatif. Populasi dalam penelitian ini adalah seluruh petani padi yang lahan pertanian padinya terdampak banjir yaitu $160 \mathrm{KK}$ dengan jumlah sampel sebanyak 62 responden. Hasil penelitian ini menunjukkan bahwa dampak banjir terhadap pendapatan petani padi di Pinggir Danau Singkarak sangat besar. Petani padi pada saat tidak terdampak banjir memperoleh pendapatan akan tetapi pada saat terdampak banjir sebagian besar petani padi mengalami kerugian. Petani padi yang memiliki luas lahan kurang dari 0,25 hektar mengalami penurunan pendapatan sebesar 96,98\%. Petani padi yang memiliki luas lahan 0,26 hektar sampai 0,50 hektar mengalami kerugian sebesar $28,65 \%$. Petani padi yang memiliki luas lahan 0,51 hektar sampai 0,99 hektar mengalami kerugian sebesar $19,91 \%$. Petani padi yang memiliki luas lahan lebih dari 1 hektar mengalami kerugian sebesar $4,32 \%$.
\end{abstract}

Kata kunci : Luas Lahan, Biaya Produksi, Hasil Pertanian, dan Pendapatan.

\section{ABSTRACT}

This purpose of this research is to know the impact of flooding on the income of rice farmers on the edge of Singkarak Lake Nagari Paninggahan, Junjung Sirih Subdistrict, Solok Regency. This type of research is descriptive with a quantitative approach. The population in this study were all rice farmers whose agricultural land was affected by flooding, namely $160 \mathrm{KK}$ with a total sample of 62 respondents. The results of this study indicate that the impact of flooding on the income of rice farmers on the edge of Singkarak Lake is very large. Rice farmers when not affected by flooding receive income but when affected by flooding most rice farmers suffer losses. Rice farmers who have a land area of less than 0.25 hectares experienced a decline in income of 96.98\%. Rice farmers who have a land area of 0.26 hectares to 0.50 hectares suffered a loss of $28.65 \%$. Rice farmers who have a land area of 0.51 hectares to 0.99 hectares suffered losses of 19.91\%. Rice farmers who have a land area of more than 1 hectare suffer a loss of $4.32 \%$.

Keywords: Land Area, Production Costs, Agricultural Products, and Revenues.

\footnotetext{
${ }^{1}$ Mahasiswa Program Studi Pendidikan Geografi

${ }^{2}$ Dosen Jurusan Geografi Fakultas Ilmu Sosial Universitas Negeri Padang
} 


\section{PENDAHULUAN}

Banjir merupakan bencana alam yang menempati urutan petama bencana yang sering menimpa beberapa daerah di Kabupaten Solok terutama di daerah Kecamatan Kubung, Kecamatan Lembah Gumanti, dan Kecamatan Junjung Sirih. Menurut Asdak (2014); Putra (2017) banjir adalah aliran sungai yang mengalir melampaui kapasitas tampungan air sungai dan menggenangi daerah sekitar. Supriyono (2014) menjelaskan bahwa banjir diartikan sebagai suatu peristiwa dimana air menggenangi daratan yang dapat menimbulkan kerugian fisik serta berdampak secara sosial dan ekonomi bagi manusia.

Menurut Kusuma (2014) banjir dapat diklasifikasikan berdasarkan proses terjadinya dan berdasarkan posisinya dari sumber banjir terhadap daerah yang digenanginya. Klasifikasi banjir berdasarkan proses terjadinya yaitureguler atau banjir biasa dan irreguler atau banjir tidak biasa. Sedangkan klasifikasi banjir berdasarkan posisi sumber banjirnya yaitu banjir lokal dan banjir bandang.

Asdak (2014) membedakan tiga faktor yang mempengaruhi banjir, yaitu elemen meteorologi, karakteristik fisik DAS dan manusia. Elemen meteorologi yang berpengaruh pada timbulnya banjir adalah intensitas, distribusi, frekuensi dan lamanya hujan berlangsung. Karakteristik fisik DAS yang berpengaruh terhadap terjadinya banjir adalah luas DAS, kemiringan lahan, ketinggian dan kadar air tanah. Manusia berperan pada percepatan perubahan penggunaan lahan untuk permukiman dan prasarana wilayah, sehinggadapat mengurangi daerah resapan saat terjadinya musim penghujan.

Supriyono (2014) mengatakan bahwa ada beberapa faktor utama yang menyebabkan terjadinya banjir yaitu; sungai, muara, peristiwa alam, manusia, dan lainnya. . Sedangkan Sa'adah (2007) menyebutkan bahwa faktorfaktor yang menyebabkan banjir diantaranya yaitu; (1) alih fungsi lahan, (2) sampah yang menumpuk, (3) rusaknya sungai dan Daerah Aliran Sungai, (4) dan curah hujan yang tinggi. Faktor yang menyebabkan banjir menjadi semakin sering terjadi dan semakin parah dampaknya yaitu terjadinya perluasan dan pertumbuhan jumlah bangunan, pembuangan sampah, pengelolaan sumberdaya alam yang tidak bijaksana, dan peningkatan jumlah penduduk.

Menurut Supriyono (2014) banjir bisa berdampak secara positif yakni; 1) persediaan air meningkat, 2) menyeimbangkan ekosistem, 3) menyuburkan tanah, 4) peremajaan kembali persawahan, 5) pembentukan minyak bumi dan 6) menjaga kelembaban tanah. Sedangkan dampak negatif banjir dapat dibedakan menjadi; dampak primer dan sekunder. Berdampak primer apabila banjir tersebut menyebabkan kerusakan fisik, sedangkan banjir yang dikatakan berdampak sekunder apabila banjir tersebut menyebabkan kerusakan dibidang sosial seperti kegagalan panen sehingga persediaan pangan terganggu. Fenomena banjir ini juga merupakan permasalahan yang hampir setiap tahun

E-ISSN : 2615-2630 
terjadi di Nagari Paninggahan Kecamatan Junjung Sirih Kabupaten Solok. Menurut Laporan Profil Kawasan Terpilih Pusat Pengembangan Desa (2003), terjadinya banjir ini dipicu oleh curah hujan sedang dengan daerahnya berada di Pinggir Danau Singkarak yang merupakan muara dari enam sungai, yakni; Sungai Sumpur, Sungai Baing, Sungai Paninggahan, Sungai Muaro Pingai, Sungai Saningbakar dan Sungai Sumani. Selain itu daerah ini juga merupakan daerah yang relatif datar, dengan kemiringan lereng kurang dari $8 \%$.

Berdasarkan data yang diperoleh dari kantor Wali Nagari Paningahan (2016) bahwa luas lahan pertanian padi yang terdampak banjir di Pinggir Danau Singkarak Nagari Paninggahan yaitu 175 ha dengan jumlah petani sebanyak 160 KK. Menurut informasi yang didapatkan dari masyarakat yang berada di Pinggir danau Singkarak Nagari Paninggahan bahwa daerah Pinggir Danau Singkarak ini mengalami kejadian banjir minimal sekali dalam setahun. Dengan adanya banjir ini dapat memberikan pengaruh terhadap pola tanam dan biaya produksi pertanian sehingga berimbas kepada hasil pertanian dan pendapatan petani padi yang lahan pertanian padinya terdampak banjir saat ada tanaman di Pinggir Danau Singkarak Nagari Paninggahan.

\section{METODE PENELITIAN}

Jenis penelitian ini yaitu penelitian deskriptif kuantitatif. Populasi penelitian ini adalah seluruh petani padi yang lahan pertaniannya terdampak banjir yang berjumlah 160 KK. Pemilihan sampel dilakukan dengan teknik simple random sampling, sehingga didapatkan sampel sebanyak 62 responden. Data penelitian ini meliputi luas lahan pertanian padi yang terdampak banjir saat ada tanaman dan pendapatan yang diperoleh petani padi pada saat tidak terdampak banjir dengan terdampak banjir, yang dapat dilihat pada biaya produksi yang dikeluarkan serta hasil pertanian yang diperoleh petani padi di Pinggir Danau Singkarak Nagari Paninggahan dalam satu kali periode tanam.

\section{HASIL DAN PEMBAHASAN}

Sebelum dibahas dampak banjir terhadap pendapatan petani padi di Pinggir Danau Singkarak Nagari Paninggahan, maka pada bagian ini perlu dikemukakan terlebih dahulu luas lahan pertanian padi yang terdampak banjir saat ada tanaman.

\section{A. Luas Lahan Pertanian Padi yang Terdampak Banjir}

Perspektif tentang lahan dilihat dari penggunaannya sebagai kegiatan ekonomi, dapat menentukan keuntungan ekonomi yang dihasilkan (Ahyuni,. 2016). Luas lahan sangat menentukan tingkat keuntungan yang didapatkan oleh petani. Luas lahan dalam penelitian ini adalah luas lahan pertanian padi yang terdampak banjir pada tahun 2016 di Pinggir Danau Singkarak Nagari Paninggahan Kecamatan Junjung Sirih Kabupaten Solok. 
Tabel 1. Distribusi Frekuensi Lahan Pertanian Padi yang Terdampak Banjir Saat Ada Tanaman.

\begin{tabular}{|c|c|c|c|c|c|c|c|}
\hline \multirow{3}{*}{ No } & \multirow{3}{*}{$\begin{array}{c}\text { Luas Lahan } \\
\text { (Hektar) }\end{array}$} & \multicolumn{4}{|c|}{$\begin{array}{c}\text { Lahan Pertanian Padi yang Terkena Banjir } \\
\text { Saat Ada Tanaman }\end{array}$} & \multirow{2}{*}{\multicolumn{2}{|c|}{ Jumlah }} \\
\hline & & \multicolumn{2}{|c|}{ Semua } & \multicolumn{2}{|c|}{ Sebagian } & & \\
\hline & & Frekuensi & $\%$ & Frekuensi & $\%$ & Frekuensi & $\%$ \\
\hline 1 & $\leq 0,25$ & & & 5 & 8,06 & 5 & 8,07 \\
\hline 2 & $0,26-0,50$ & 6 & 9,68 & 12 & 19,35 & 18 & 29,03 \\
\hline 3 & $0,51-0,99$ & 6 & 9,68 & 4 & 6,45 & 10 & 16,13 \\
\hline \multirow[t]{2}{*}{4} & $\geq 1$ & 21 & 33,87 & 8 & 12,91 & 29 & 46,77 \\
\hline & Jumlah & 33 & 53,23 & 29 & 46,77 & 62 & 100 \\
\hline
\end{tabular}

Sumber: Pengolahan Data Primer, 2018.

Data Tabel 1 memperlihatkan bahwa, luas lahan yang dimiliki oleh petani padi di Nagari Paninggahan cukup bervariasi, mulai dari 0,25 hektar sampai lebih dari 1 hektar. Jumlah petani terbanyak $(46,77 \%)$ adalah petani yang memiliki lahan lebih dari 1 hektar. Bila mengacu kepada kriteria penguasaan lahan menurut lincolin (2004), luas lahan yang lebih dari 1 hektar diklasifikasikan menjadi lahan yang luas. Sehingga lahan pertanian padi di Pinggir Danau Singkarak Nagari Paninggahan yang terdampak banjir tergolong luas.

Selanjutnya, dapat dilihat pada kejadian banjir tahun 2016 dari 62 responden ternyata sebagian besar $(53,23 \%)$ petani menyatakan semua lahan pertanian yang mereka miliki terdampak banjir, sedangkan sisanya (46,77\%) menyatakan bahwa lahan pertanian mereka juga terdampak banjir meskipun hanya sebagian dari lahan yang dimiliki.

Apabila dilihat dari luas keseluruhan, lahan pertanian padi yang terdampak banjir di Pinggir Danau Singkarak Nagari Paninggahan pada tahun 2016 dari 62 responden adalah
50,75 hektar dengan rata-rata 0,82 hektar per responden.

\section{B. Pendapatan Petani Padi}

Pendapatan petani padi di Pinggir Danau Singkarak Nagari Paninggahan dapat dilihat pada biaya produksi (persemaian, penanaman, pemeliharaan, panen dan pasca panen) yang dikeluarkan dan hasil pertanian yang diperoleh dalam satu kali periode tanam.

1. Biaya Produksi Pertanian Padi yang Dikeluarkan Pada Saat Tidak Terdampak Banjir dengan Terdampak Banjir

Biaya produksi adalah biaya yang dikeluarkan oleh petani dalam proses produksinya. Biaya produksi dalam penelitian ini meliputi biaya persemaian, persiapan lahan, penanaman, pemeliharaan serta biaya panen dan pascapanen selama satu kali periode tanam. 
Tabel 2. Perbandingan Rata-Rata Biaya Produksi Pertanian Padi Pada Saat Tidak Terdampak Banjir dengan Terdampak Banjir.

\begin{tabular}{llrrrr}
\hline & Luas Lahan & \multicolumn{2}{c}{ Biaya yang Dikeluarkan } & & \multicolumn{2}{c}{$\begin{array}{c}\text { Persentase } \\
\text { No }\end{array}$} & $\begin{array}{c}\text { Pada Saat Tidak } \\
\text { Terdampak } \\
\text { Banjir (Rp) }\end{array}$ & $\begin{array}{c}\text { Pada Saat } \\
\text { Terdampak } \\
\text { Banjir (Rp) }\end{array}$ & \multicolumn{1}{c}{$\begin{array}{c}\text { Selisih } \\
(\mathbf{R p})\end{array}$} & $\begin{array}{c}\text { Penurunan } \\
(\boldsymbol{\%})\end{array}$ \\
\hline 1 & $\leq 0,25$ & 1.468 .000 & 594.000 & 874.000 & 59,54 \\
2 & $0,26-0,50$ & 2.318 .000 & 1.329 .000 & 989.000 & 42,67 \\
3 & $0,51-0,99$ & 3.362 .000 & 2.203 .000 & 1.159 .000 & 34,47 \\
4 & $\geq 1$ & 5.369 .000 & 3.534 .000 & 1.835 .000 & 34,18 \\
\hline
\end{tabular}

Sumber: Pengolahan Data Primer, 2018.

Data Tabel 2 memperlihatkan bahwa perbandingan rata-rata biaya produksi pertanian padi saat tidak terdampak banjir dengan terdampak banjir, oleh petani yang memiliki luas lahan kurang dari 0,25 hektar mengalami penurunan biaya sebesar $59,54 \%$, petani yang memiliki luas lahan 0,26 hektar sampai 0,50 hektar mengalami penurunan biaya sebesar $42,64 \%$, petani yang memiliki luas lahan 0,51 hektar sampai 0,99 hektar mengalami penurunan biaya sebesar $34,47 \%$ dan petani yang memiliki luas lahan lebih dari 1 hektar mengalami penurunan sebesar $34,18 \%$.

2. Hasil Pertanian yang Diperoleh Pada Saat Tidak Terdampak Banjir dengan Terdampak Banjir

Hasil pertanian akan berpengaruh terhadap pendapatan. Apabila hasil pertaniannya meningkat maka pendapatan akan ikut meningkat, begitu juga sebaliknya apabila hasil pertanian menurun maka pendapatan petani akan menurun.Hasil pertanian dalam penelitian ini yaitu dalam bentuk kilogram $\quad(\mathrm{kg}) \quad$ beras.

Tabel 3. Perbandingan Rata-Rata Hasil Pertanian Padi Pada Saat Tidak Terdampak Banjir dengan Terdampak Banjir.

\begin{tabular}{llrrrr}
\hline No & $\begin{array}{c}\text { Luas Lahan } \\
\text { (Hektar) }\end{array}$ & $\begin{array}{c}\text { Pada Saat Tidak } \\
\text { Terdampak } \\
\text { Banjir (Kg Beras) }\end{array}$ & $\begin{array}{c}\text { Pada Saat } \\
\text { Terdampak }\end{array}$ & $\begin{array}{c}\text { Selisih } \\
\text { (Kanjir (Kg Beras) }\end{array}$ & $\begin{array}{c}\text { Persentase } \\
\text { Penurunan(\%) }\end{array}$ \\
\hline 1 & $\leq 0,25$ & 266 & 58 & 208 & 78,19 \\
2 & $0,26-0,50$ & 454 & 51 & 403 & 88,77 \\
3 & $0,51-0,99$ & 603 & 140 & 463 & 76,78 \\
4 & $\geq 1$ & 1.141 & 293 & 848 & 74,32 \\
\hline
\end{tabular}

Sumber: Pengolahan Data Primer, 2018.

Data Tabel 3 memperlihatkan bahwa perbandingan rata-rata hasil pertanian padi saat tidak terdampak banjir dengan terdampak banjir oleh petani yang memiliki luas lahan kurang dari 0,25 hektar mengalami penurunan hasil sebesar $78,19 \%$, petani yang memiliki luas lahan 0,26 hektar sampai 0,50 hektar mengalami penurunan hasil sebesar $88,77 \%$, petani yang memiliki luas lahan 0,51 hektar sampai 0,99 hektar mengalami penurunan hasil 
sebesar $76,78 \%$ dan petani yang

penghasilan dari keluarga yang memiliki luas lahan lebih dari 1 hektar disumbangkan kepada pemenuhan mengalami penurunan hasil sebesar $74,32 \%$.

3. Pendapatan Petani Padi Pada Saat

Tidak Terdampak Banjir dengan

Terdampak Banjir

Pendapatan menurut Bangun kebutuhan. Harga beras per kilogram yaitu Rp 11.000. Sehingga seluruh total penerimaan (hasil pertanian) dijadikan kedalam bentuk rupiah, setelah itu di kurang dengan total produksi (biaya produksi) maka akan di peroleh (1987) dalam Surtani (1994) adalah pendapatan bersih.

Tabel 4. Perbandingan Rata-Rata Pendapatan Petani Padi Pada Saat Tidak Terdampak Banjir dengan Terdampak Banjir.

\begin{tabular}{|c|c|c|c|c|c|c|}
\hline \multirow[b]{2}{*}{ No } & \multirow[b]{2}{*}{$\begin{array}{c}\text { Luas } \\
\text { Lahan } \\
\text { (Hektar) }\end{array}$} & \multicolumn{2}{|c|}{ Pendapatan Petani Padi } & \multirow[b]{2}{*}{$\begin{array}{l}\text { Selisih } \\
(\mathbf{R p})\end{array}$} & \multicolumn{2}{|c|}{$\begin{array}{c}\text { Persentase Penurunan } \\
\text { Pendapatan }(\%)\end{array}$} \\
\hline & & $\begin{array}{c}\text { Pada Saat } \\
\text { Tidak } \\
\text { Terdampak } \\
\text { Banjir (Rp) } \\
\end{array}$ & $\begin{array}{c}\text { Pada Saat } \\
\text { Terdampak } \\
\text { Banjir (Rp) }\end{array}$ & & $\begin{array}{c}\text { Tidak Mengalami } \\
\text { Kerugian } \\
\text { (Pendapatan) }\end{array}$ & $\begin{array}{c}\text { Mengalami } \\
\text { Kerugian }\end{array}$ \\
\hline 1 & $\leq 0,25$ & 1.459 .000 & 44.000 & 1.415 .000 & 96,98 & \\
\hline 2 & $0,26-0,50$ & 2.674 .000 & -766.0 & 3.440 .000 & & 28,65 \\
\hline 3 & $0,51-0,99$ & 3.330 .000 & -663.000 & 3.993 .000 & & 19,91 \\
\hline 4 & $\geq 1$ & 7.181 .000 & -310.000 & 7.491 .000 & & 4,32 \\
\hline
\end{tabular}

Sumber: Pengolahan Data Primer, 2018.

Data Tabel 4 memperlihatkan bahwa perbandingan rata-rata pendapatan petani padi saat lahannya tidak terdampak banjir dengan terkena banjir oleh petani yang memiliki luas lahan kurang dari 0,25 hektar mengalami penurunan pendapatan sebesar $96,98 \%$, petani yang memiliki luas lahan 0,26 hektar sampai 0,50 hektar mengalami kerugian sebesar $28,65 \%$, petani yang memiliki luas lahan 0,51 hektar sampai 0,99 hektar mengalami kerugian sebesar 19,91\% dan petani yang memiliki luas lahan lebih dari 1 hektar mengalami kerugian sebesar 4,32\%. Dapat dilihat pada gambar peta perbandingan rata-rata pendapatan petani padi berikut ini. 

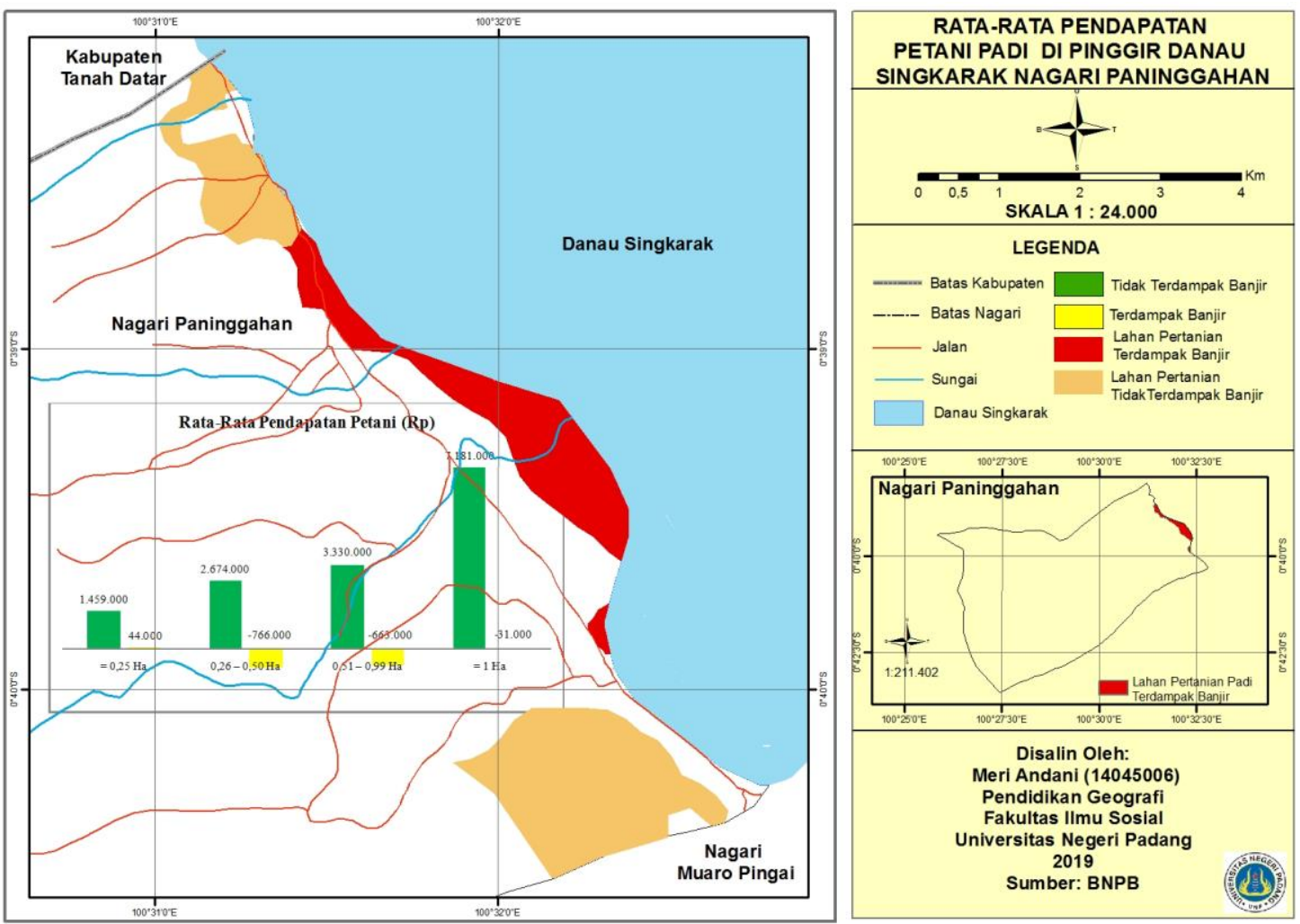

Gambar 1: Perbandingan Rata-Rata Pendapatan Petani Padi.

\section{KESIMPULAN}

Dampak banjir terhadap pendapatan petani padi di Pinggir Danau Singkarak Nagari Paninggahan sangatlah besar, petani yang pada saat tidak terdampak banjir memperoleh pendapatan, akan tetapi pada saat terdampak banjir sebagian besar mengalami kerugian. Pendapatan yang diperoleh petani yang memiliki luas lahan kurang dari 0,25 hektar mengalami penurunan dengan persentase sebesar $96,98 \%$, petani yang memiliki luas lahan 0,26 hektar sampai 0,50 hektar mengalami kerugian dengan persentase sebesar $28,65 \%$, petani yang memiliki luas lahan 0,51 hektar sampai 0,99 hektar mengalami kerugian dengan persentase sebesar $19,91 \%$, petani yang memiliki luas lahan lebih dari 1 hektar mengalami kerugian dengan persentase sebesar $4,32 \%$.

\section{DAFTAR PUSTAKA}

Ahyuni. 2016. Perencanaan Penggunaan Lahan. Kencana. Jakarta.

Asdak, C. 2014. Hidrologi dan Pengelolaan Daerah Aliran Sungai. UGM University Press. Yogyakarta

Kusuma. 2014. Banjir, Beberapa Masalah dan Metode Pengendaliannya Dalam Perspektif Lingkungan. Pustaka Pelajar. Yogyakarta.

Lincolin, Arsyad. 2004. Ekonomi Pembangunan. Sekolah Tinggi Ilmu Ekonomi YKPN. Yogyakarta. 
Panitia Laporan Profil Kawasan Terpilih Pusat Pengembangan Desa. 2003. Pengembangan Perumahan dan Permkiman Kawasan Nagari Paninggahan Kecamatan Junjung Sirih Kabupaten Solok Sumatera Barat. Harrisa Consultan. Padang.

Sa'adah, Sumiati. 2007. Seri Bencana Alam Banjir. Bandung: Karya Putri Darwati

Putri, Y.E., Ahyuni dan Purwaningsih, E (2018). PENENTUAN LAHAN PERTANIAN PANGAN BERKELANJUTAN
(LP2B) KOMODITI PADI SAWAH DI KABUPATEN DHARMASRAYA. JURNAL BUANA, l(1), 120-120.

Supriyono, Primus. 2014. Seri Pendidikan Pengurangan Risiko Bencana Banjir. Andi Offset. Yogyakarta.

Surtani. 1994. Studi tentang Tingkat Pendapatan dan Pemasaran Sebelum dan Sesudah Adanya Tempat Pelelangan Ikan (TPI) di Kecamatan Bungus Teluk Kubung Kodya Padang. Laporan Penelitian, IKIP Padang 